\title{
The outcomes of family and consumer leadership education: creating positive change in disability policy and practice
}

\section{BACKGROUND}

When individuals with disabilities are trained in evidenced based practices and how to advocate for themselves and their families, they are best able to ensure that services and supports meet their needs and create and realize a positive vision for their future.

\section{PARTICIPANTS AND PROCEDURE}

In New Hampshire in the United States a Leadership Series provided seven weekend training sessions to an annual cohort of about 25 family members and 10 adults with disabilities about better practices in service provision, defining a vision for the future, and community organizing and advocacy strategies, using informational sessions and participation in small work groups.

\section{RESULTS}

A total of 100 participants completing the Series over a sixyear period completed pre and post surveys consisting of both closed-ended and open-ended questions. Respondents reported highly significant increases in their knowledge about service provision and advocacy strategies, significant increases in their clarity of vision for six out of seven life domains, and significant increases in their membership in community organizations and frequency of advocacy activities.

\section{CONCLUSIONS}

The Leadership Series fostered increased efforts to create positive change in the lives of the participants and their family members with disabilities and in the services and supports provided to family members with disabilities.

KEY WORDS

families; advocacy; community inclusion; disability

ORGANIZATION - Institute on Disability, University of New Hampshire, Durham, USA

AUthors' Contributions - A: Study design - B: Data collection - C: Statistical analysis - D: Data interpretation .

E: Manuscript preparation · F: Literature search · G: Funds collection

Corresponding Author - Mary Schuh, Ph.D., Institute on Disability, University of New Hampshire, 10 West Edge,

Durham, NH 03824, USA, e-mail: mary.schuh@unh.edu

to CITE THIS ARTICLE - Schuh, M., Hagner, D., Dillon, A., \& Dixon, B. (2015). The outcomes of family and consumer

leadership education: creating positive change in disability policy and practice. Health Psychology Report, 3(2),

115-122. DOI: $10.5114 /$ hpr.2015.50173

RECEIVED 19.12.2014 · REVIEWED 27.01.2015 - ACCEPTED 18.03.2015 · PUBLISHED 30.04.2015 


\section{BACKGROUND}

Significant changes are underway in service design and expectations for individuals with disabilities. As evidenced by the United Nations' Convention on the Rights of Persons with Disabilities (United Nations Department of Economic and Social Affairs, 2006), a fundamental shift in perspective is evident throughout the world away from social benevolence toward the acknowledgement of, and respect for, the capabili-
Mary Schuh, David Hagner, Ann Dillon, Beth Dixon ties and rights of individuals with disabilities (Powers et al., 2012). This new perspective recognizes a person with a disability as a positive contributor within resilient and capable family systems (Turnbull, Taylor, Erwin, \& Soodak, 2006). An important implication of this new perspective is a policy shift toward consumers playing essential roles in the design, implementation, and evaluation of disability services.

Many programs and services are designed to deliver a prescribed set of services to groups of people with similar types or severity of disabilities, and who are viewed as having similar needs, neglecting the fact that individuals differ widely from one another and require individualized and personalized supports (Soresi, Nota, \& Wehmeyer, 2011). Such individualized supports should ideally be controlled by the consumer and/or family (Turnbull et al., 2007). Individuals with disabilities and their families are often in the best position to know what they need (Deguara, Jelasi, Micallef, \& Callus, 2012); while professionals, however well-meaning, are often seriously misinformed about the perspectives and needs of the families of individuals with disabilities (Green, 2007). Thus, it is important for individuals with disabilities and their families to learn how to advocate for themselves (Vargas et al., 2012) and to effect systems change (Barenock \& Weick, 1998).

Given that people with disabilities have historically seemed all but invisible in society (Vargas et al., 2012), it is not surprising that many experience a "sense of impotence" (Soresi et al., 2011, p. 22) and feel that their voices will not be heard, or only give them a reputation for causing trouble. Moreover, advocacy undertaken in isolation can be stressful (Wang, Mannan, Poston, Turnbull, \& Summers, 2004). Policies governing services are extremely complex and confusing (Chambers, Hughes, \& Carter, 2004). But systematic training and support can lay the foundation for effective action through providing the up-to-date pertinent information essential for meaningful decision-making and influence (Knox, Parmenter, Atkinson, \& Yazbeck, 2000), and providing practical experience to develop advocacy skills (Caldwell, 2010).

The need for to up-to-date information and training resulted in the development of educational programs designed to meet the needs of both families caring for their daughters and sons with disabilities and individuals with disabilities learning to take charge of the supports and services in their own lives. Group training sessions have been found to be effective for teaching leadership and advocacy skills to high school students with disabilities (Grenweldge \& Zhang, 2012), adults with mental illness and their families (Hess, Clapper, Hoekstra, \& Gibson, 2001; Stringfellow \& Muscari, 2003), and the families of children with disabilities (Vargas et al., 2012).

One such training program, the New Hampshire Leadership Series (NH Leadership) was developed to provide up-to-date training and information to individuals with disabilities and their family members. New Hampshire Leadership was modeled after Minnesota's Partners in Policymaking ${ }^{\mathrm{TM}}$ program which was initially developed in 1987 and validated though studies in the mid-1990's. A study of the Partners in Policymaking Program by Balcazar, Keys, Bertram, and Rizzo (1996) investigated two outcome variables: number of advocacy activities and number of advocacy outcomes. Participant responses on each variable were significantly higher following training. Cunconan-Lehr and Brotherson (1996) conducted a qualitative study of Partners in Policymaking graduates and found that the training provided families with practical advocacy skills, opportunities for networking with other families, and a greater sense of self-confidence. Since its inception, the program has been replicated or adapted in 46 US states and in the Netherlands and the United Kingdom (Reynolds, 2011).

The NH Leadership Series began in 1988 at the University of New Hampshire's (UNH) Institute on Disability. Since then, it has been held each year and has graduated over 900 participants. The Series is designed to provide family members and individuals with disabilities information and strategies to effectively impact local, state, and national organizations on issues related to disability policy and practice.

The Leadership Series is sponsored by the UNH Institute on Disability in collaboration with the Developmental Disabilities Council, People First, the New Hampshire Bureau of Developmental Services, the New Hampshire Department of Education, and several other organizations. The current study was designed to expand upon previous research by examining the impact of the Leadership Series on multiple advocacy variables, and on the level of knowledge and clarity of vision for the future that provide the foundation for advocacy activity.

The study was designed to answer the following research question: Does participation in NH Leadership increase (a) one's knowledge about best practices and advocacy strategies, (b) the clarity of one's vision for their future or the future of one's family member, and (c) one's ability to affect change through membership in civic organizations and participation in advocacy activities? 


\section{THE NEW HAMPSHIRE LEADERSHIP SERIES}

The NH Leadership Series consists of seven weekend trainings, on Friday afternoon and all day Saturday, approximately one month apart, held at a hotel or conference center, with all meals and overnight accommodations provided. Approximately 30-35 participants attend each series. The Series is coordinated and taught by staff of the UNH Institute on Disability - some of whom are themselves Leadership Series graduates - with assistance from guest speakers each weekend who are experts on the specific topic covered. The coordinator provides readings and handouts for each session, as well as fieldwork assignments throughout the seven sessions. Participants are divided into five small Home Groups, with a leader assigned to each group, for small-group discussion following informational sessions. The curriculum for the sessions is as follows:

1. History of the disability movement. This session describes the history of services for, and perceptions of, people with disabilities, emphasizing the experiences of New Hampshire. The power and influence of parents in the closing of the $\mathrm{NH}$ state institution for people with developmental disabilities is a highlight of the weekend. The training weekend takes place on the grounds of the former state institution. A panel of former residents and employees of the state institution present their stories, and serve as a powerful reminder that this past should never be repeated. An overview of the remainder of the series is provided. Participants are introduced to their Home Group, the small group designed to support one another for the remainder of the Series, and to their Group Leader.

2. Creating a vision. This session features talks by family members who have created a full life for their son, daughter, and/or themselves by making creative use of and often going beyond the traditional services offered to them. This vision encompasses full participation in all aspects of community life including regular education, employment, meaningful relationships, and community living. Participants share their visions with their Home Groups, and during this session they also form Action Groups to address specific problems, based on the common issues and challenges identified by groups of participants. Participants remain in the same Home Group and Action Group throughout the Series.

3. Community organizing. This session presents strategies for beginning and sustaining grassroots-level organizing. The focus is on building allies and sustaining power in order to create change. Participants learn how to run effective meetings and the art of negotiation. During this session they also practice conducting one-on-one interviews to assess and understand the importance of self-interest while engaging one another in supporting a cause, and learn to recognize and deal with their own barriers to effective advocacy.

4. Inclusive education. In this session, the benefits, values, and research supporting students with disabilities attending their neighborhood schools and participating full time in general education classes with support are presented by educational experts and enhanced with personal stories. Specific strategies to achieve inclusive education are demonstrated, including alternative forms of communication and positive behavioral supports. This session also considers the importance of facilitating friendships between students with and without disabilities and participation in community recreation and other extracurricular activities.

5. A quality adult life. Tools and options for life as an adult in the community are explored in this session within the context of typical and healthy adult lifestyles. Choice and control of resources and person-centered planning are discussed by presenters who are using this option. Other topics include assistive technology, transportation, post-secondary education, supported employment in the open job market, and choice and control of one's residence.

6. The legislative process. During this session, participants are trained in how a bill becomes a law at the state and federal levels, and work to identify current critical federal and state legislative issues. This session is typically held in the state capitol building in an effort to orient participants to the reality of the political process. Participants learn how to conduct a meeting with a legislator, and are responsible for inviting their own state legislators to attend the session. They also attend a mock legislative hearing session which is led by a leadership graduate.

7. Culmination and celebration. In this final session, each Action Group presents the work of their group which includes the focus of their issue, how they organized as a group to address the challenge, what impact they made to date, and what they learned about the process of working as a team. A graduation ceremony and celebration end the Series, and as part of this culmination event they meet and form connections with former graduates. Continued participation and peer support through the Leadership website and other social media is encouraged. Additionally, participants are encouraged to continue to expand their leadership skills and experience through membership in community organizations relevant to their concerns.

\section{PARTICIPANTS AND PROCEDURE}

Recruitment for the NH Leadership Series is an ongoing process. The Leadership website contains information about the Series and individuals can complete an online application any time during the year
Family and consumer leadership 
Mary Schuh,

David Hagner, Ann Dillon, Beth Dixon as well as nominate someone to apply. Once a year, past graduates of the Series and state leaders in the disability field are encouraged to nominate individuals to apply to participate in the Leadership Series. Each person nominated is encouraged to complete the online application. Approximately 60 individuals apply each year and about 35 are selected. Selection criteria include representation by both genders, all geographic areas of the state, a variety of ages and disabilities, and emerging leadership qualities as evidenced in the application narrative and personal references. The goal is also to accept a mix of approximately $80 \%$ family members and $20 \%$ adults with disabilities. Partnerships across the state allow for extensive recruitment efforts through their networks.

Between September, 2004 and June, 2010, the Series was held 6 times, and 197 individuals completed the training. During the following 2 years, follow-up investigation was suspended during a period of reorganizing how the training was administered. Each cohort completed an identical pre-survey prior to beginning the training, and then a post-survey identical to the pre-survey immediately following the final session. Beginning in 2010, online surveys replaced the paper surveys. The surveys contained both closed-ended questions for quantitative and open-ended questions to collect anecdotal information. Table 1 summarizes the participant demographics.

Directional repeated measures $t$-tests with the level of significance set at .05 were used to analyze pre-post differences in study variables. Anecdotal information from answers to open-ended questions and postings on the Leadership website were used to illustrate quantitative findings. The qualitative process of comparing and contrasting pre test responses to post test responses guided the deductive process of examining, identifying, and recording the themes illustrated in the

Table 1

Participant demographic information

\begin{tabular}{ccc}
\hline Role & $\begin{array}{c}\text { Parent of individual with disability } \\
\text { Other family member }\end{array}$ & 60 \\
& $\begin{array}{c}\text { Individual with disability } \\
\text { Other (e.g. interested community } \\
\text { member, service provider) }\end{array}$ & 19 \\
Gender & Male & 16 \\
Education & Female & 84 \\
& Elementary & 0 \\
High School & 21 \\
2-Year College & 3 \\
4-Year College & 44 \\
Post Graduate & 32 \\
\hline
\end{tabular}

findings as directly correlated with the survey questions.

\section{RESULTS}

Of 197 participants completing training, 100 participants completed both pre- and post-surveys over the 6 years of the study, a $51 \%$ response rate.

\section{KNOWLEDGE ABOUT BEST PRACTICES}

Participants were asked how comfortable they were with their understanding of best practices in relation to 10 categories of disability service provision, and three important advocacy practices. Responses ranged from 0 (not at all) to 5 (could teach others). The pre-post increase was highly significant - at greater than a .001 level - for each of the 10 disability service provision topics: (a) NH Disability History, (b) Family Support, (c) Early Care and Early Childhood Education, (d) Primary, Middle, and Secondary Education, (e) Assistive Technology, (f) Positive Behavior Supports, (g) Person-Centered Planning, (h) Community Recreation, (i) Community Employment, and (j) Community Housing and Supports. The mean pre and post knowledge differences for the three categories of advocacy strategies were also significant at the .001 level: (a) The Art of Negotiation, (b) Change Through Legislation, and (c) Community Organizing. Table 2 summarizes the means and $t$ statistics for each topic.

At the beginning of the Leadership Series, participants often reported a lack of knowledge and information about supports and services that they were not directly connected to or considering as a possibility in their lives. For example, unless a parent had gone through a conflict-oriented experience, they were not familiar with the organizations whose mission was to advocate on behalf of individuals with disabilities and their families. If they had a young child with a disability, parents were not aware of the possibilities and resources available to support their child as she/he grew into adulthood. For many individuals, while they may have had an expansive vision for the future for themselves or their family member, they may have been unaware of the resources to support them, and therefore reluctant to pursue a goal that might conflict with what their service provider typically provides. By the completion of the Leadership Series, graduates expressed an increased knowledge of evidence-based practices and the supports and services available to achieve these practices in their own lives. The following quote is an example: "The variety of approaches to communication and strategies to affect change were invaluable tools. I leave Leadership with a big bag of tricks to improve the quality of life for me and my family". 
Mean participant knowledge levels before and after leadership training

\begin{tabular}{|c|c|c|c|c|c|c|}
\hline \multirow[t]{2}{*}{ Knowledge of service practices } & \multicolumn{2}{|c|}{ Pre } & \multicolumn{2}{|c|}{ Post } & \multirow[t]{2}{*}{$t$} & \multirow[t]{2}{*}{$p$} \\
\hline & Mean & $S D$ & Mean & $S D$ & & \\
\hline NH disability history & 2.66 & 0.97 & 4.05 & 0.71 & 12.31 & $<.001$ \\
\hline Family support & 3.32 & 0.99 & 3.91 & 0.87 & 5.31 & $<.001$ \\
\hline Early childhood care and education & 3.39 & 0.99 & 3.80 & 0.84 & 3.44 & $<.001$ \\
\hline Primary, middle, secondary education & 3.34 & 0.98 & 3.96 & 0.82 & 5.72 & $<.001$ \\
\hline Assistive technology & 2.76 & 0.88 & 3.39 & 0.28 & 5.72 & $<.001$ \\
\hline Positive behavior supports & 3.03 & 1.06 & 3.71 & 1.03 & 5.41 & $<.001$ \\
\hline Person-centered planning & 2.79 & 1.04 & 3.61 & 0.99 & 6.83 & $<.001$ \\
\hline Community recreation & 2.66 & 0.10 & 3.24 & 0.94 & 4.63 & $<.001$ \\
\hline Community employment & 2.38 & 0.96 & 3.05 & 0.89 & 6.32 & $<.001$ \\
\hline Community housing and supports & 2.19 & 0.96 & 3.02 & 0.71 & 7.40 & $<.001$ \\
\hline \multirow[t]{2}{*}{ Knowledge of advocacy strategies } & \multicolumn{2}{|c|}{ Pre } & \multicolumn{2}{|c|}{ Post } & $t$ & $p$ \\
\hline & Mean & $S D$ & Mean & $S D$ & & \\
\hline The art of negotiation & 2.86 & 1.12 & 3.76 & 0.89 & 7.89 & $<.001$ \\
\hline Change through legislation & 2.68 & 1.09 & 3.99 & 0.78 & 12.21 & $<.001$ \\
\hline Community organizing & 2.71 & 1.03 & 3.87 & 0.74 & 9.86 & $<.001$ \\
\hline
\end{tabular}

\section{CLARITY OF VISION AND PLANS}

As part of the Leadership Series, participants are encouraged to define a vision for a positive future for themselves or their family member with a disability. Participants were asked to rate the adequacy of their current plans and clarity of their vision in relation to eight topic areas. Potential responses ranged from $0=$ no plan and unclear vision to $4=$ well-developed plan and very clear vision. Participants were also asked to rate the clarity of their vision for public policies needed to support the inclusion of individuals with disabilities in society.

For one topic, Elementary and Secondary Education, the pre-post increase in clarity of vision increased but not to a statistically significant level. The pre-post increase was significant for each other issue, as follows: (a) Post-Secondary Education, (b) Home Ownership, (c) Management of Supports, (d) Self-Determination, (e) Employment, (f) Social Relationships and Friendship, and (g) Recreation, Clubs and Sports. Respondents also indicated a highly significant increase in the clarity of their vision for public policies. Table 3 summarizes the means and $t$ statistics for each topic.

For each Leadership Series participant, the entry point was their personal experience, defined primarily by the information provided to them by professionals such as doctors and related service providers in the field of disability. This information often presented a narrow view of what the future could hold and often represented the limited knowledge of a service provider, often influenced by geographic location and local resources. For example, one parent of a young child with Down syndrome was told by a pediatrician that her daughter would likely be educated in a segregated school and as an adult live in a group home and work in a sheltered workshop. This same parent completed the Leadership Series with a vision that included her daughter graduating from a regular high school, entering college, and living and working in the community with friends. Not only did her vision expand for her family, she developed skills to help turn that vision into reality. As this individual stated, "Leadership brought us a new way of thinking about our daughter, our family, and our futures. The support was excellent, the knowledge was life-changing, and through the connections to other families we have made long lasting friends and allies”.

\section{MEMBERSHIP IN ORGANIZATIONS}

Participants indicated their membership in organizations concerned with the welfare of individuals with disabilities or the quality of civic life in general. The overall mean level of membership increased from 1.70 to 2.60 , a statistically significant amount $(t=2.92$, $p=.002)$. Participants increased their membership in disability organizations and organizations concerned with wider social issues by about the same amount.
Family and consumer leadership 
Table 3

Mean participant clarity of vision levels before and after leadership training

\begin{tabular}{|c|c|c|c|c|c|c|}
\hline \multirow[t]{2}{*}{ Individual-level vision for the future } & \multicolumn{2}{|c|}{ Pre } & \multicolumn{2}{|c|}{ Post } & \multirow[t]{2}{*}{$t$} & \multirow[t]{2}{*}{$p$} \\
\hline & Mean & $S D$ & Mean & $S D$ & & \\
\hline Primary and secondary education & 3.14 & 0.65 & 3.25 & 0.69 & 1.17 & .122 \\
\hline Post-secondary education & 2.63 & 0.66 & 2.78 & 0.70 & 1.75 & .042 \\
\hline Home ownership & 2.19 & 0.89 & 2.49 & 0.81 & 2.52 & .007 \\
\hline Management of supports & 2.56 & 0.76 & 2.83 & 0.64 & 2.65 & .005 \\
\hline Self-determination & 2.86 & 0.72 & 3.13 & 0.64 & 2.61 & .005 \\
\hline Employment & 2.70 & 0.75 & 2.91 & 0.78 & 2.27 & .013 \\
\hline Social relationships and friendship & 3.03 & 0.46 & 3.23 & 0.58 & 2.95 & .002 \\
\hline Recreation, clubs and sports & 2.93 & 0.62 & 3.28 & 0.57 & 4.27 & $<.001$ \\
\hline \multirow[t]{2}{*}{ Community-level vision for the future } & \multicolumn{2}{|c|}{ Pre } & \multicolumn{2}{|c|}{ Post } & $t$ & $p$ \\
\hline & Mean & $S D$ & Mean & $S D$ & & \\
\hline Public policies & 2.53 & 0.73 & 3.15 & 0.57 & 5.73 & $<.001$ \\
\hline
\end{tabular}

Leadership graduates serve on school boards, family support teams and councils, judicial benches, local and state government, and other community boards. Additionally, leadership graduates hold paid leadership positions in service delivery organizations as well as organizations promoting disability rights and social justice. Initially, participants either did not understand the importance of or feel that they could be effective in meeting with elected officials, directors of organizations, and other human service and educational leaders as strategies to create change in policy and practice. Consistently, participants reported that the community organizing and legislative sessions had a powerful impact on their personal level of comfort and skill regarding speaking out about issues important to themselves and/or their family. As a result of these sessions, many individuals have gone on to run for public office and have successfully been elected. The current Governor of $\mathrm{NH}$, the parent of a young man with significant disabilities, is a graduate of the Leadership Series.

\section{PARTICIPATION IN ADVOCACY ACTIVITIES}

Participants were asked to indicate the level in which they participate in three types of advocacy activities: (a) Meeting with community leaders, (b) Speaking out in public, and (c) Seeking additional knowledge. Responses ranged from $1=$ never to $4=$ often. As Table 4 indicates, the mean level each activity increased by was a statistically significant amount.

Responding to open-ended questions, graduates often reported renewed energy and a commitment to active civic participation. As one participant stated, "Having attended the legislative session, I am absolutely sure my actions will change. I intend to be a truly informed person - not only for personal concerns, but also for community education. My intention is to be known as a contact - one who knows!".

During this period, with substantial contributions from Leadership graduates, bills were passed into law by the NH Legislature to create a comprehensive system of family support, end the waiting list for adult services, and to reduce and eliminate restraint and seclusion practices in schools. Additionally, a number of graduates have been instrumental in the development of new organizations designed to promote positive change for people with disabilities and their families. One of these new organizations, Advocates Building Lasting Equality (ABLE) is staffed entirely by graduates of the Leadership Series and maintains almost 200 dues paying members who address current chal-

Table 4

Mean levels of participation in advocacy activities before and after leadership training

\begin{tabular}{lcccccr}
\hline \multicolumn{1}{c}{ Individual-level vision for the future } & \multicolumn{2}{c}{ Pre } & \multicolumn{3}{c}{ Post } & \multirow{2}{*}{$p$} \\
\cline { 2 - 5 } & Mean & $S D$ & Mean & $S D$ & & \\
\hline Meeting with community leaders & 2.72 & 0.79 & 3.01 & 0.78 & 3.44 & $<.001$ \\
Speaking out in public & 2.85 & 0.96 & 3.25 & 0.79 & 4.16 & $<.001$ \\
Seeking additional knowledge & 3.47 & 0.61 & 3.67 & 0.61 & 2.21 & .015 \\
\hline
\end{tabular}


lenges in the disability arena through the strategies of grass roots community organizing. Issues addressed by ABLE include: improving health care and increasing physical accessibility in public places.

\section{DISCUSSION}

This study highlights the impact of a series of leadership training sessions on parents and individuals with disabilities' (a) knowledge about best practices in the field of disability, (b) ability to develop a clarity of vision and plans for themselves and/or their family members, (c) membership and participation in organizations affecting their lives, and (d) participation in advocacy activities. It is apparent that the program fostered increased efforts to create positive change in their own lives and in the services and supports to family members with disabilities. There was no statistically significant difference observed in a family's vision for elementary education - and this was most likely due to the fact that respondents reported a high level of clarity on this issue on the pre-survey.

The effectiveness of the model seems to derive as much from the community of support that continues beyond the training, with graduates supporting and encouraging one another, as from the training itself. Substantial positive changes in disability services have taken place during this time in New Hampshire, including new legislation resulting in improved policies and practices for individuals with disabilities. Leadership graduates have also helped improve the internal policies and administration of organizations in which they have played a leadership role. There is substantial anecdotal evidence that graduates attribute their ability to play key leadership and advocacy roles in bringing about these changes to their participation in the NH Leadership Series. The following statement from a leadership graduate is an example.

The best decision I made in many years was accepting a nomination into the NH Leadership Series. I knew I had a spirit within me to do more. However, I needed a roadmap, I needed a mentor, and ultimately I needed all of the individuals who educated me through this program. I learned the value of working as a team instead of taking the world on by myself.

Since its inception, sustaining the NH Leadership Series financially has been a complex challenge. The Series was launched with limited governmental funding as a pilot program. Based on successful outcomes from the first year, state government departments responsible for disability services and Series graduates made a commitment to sustain the event. As a result, the Series has been in place for 25 years with funding provided from a variety of sources including individual donations, governmental sources, small grants, and corporate sponsorships.
Leadership staff have consulted throughout the Unites States and internationally on strategies to create and sustain leadership opportunities for family members and individuals with disabilities. Recent consultation has taken place with Scotland, Slovakia, Belarus, and Morocco. Consultation of this nature maintains a keen eye toward cultural and governmental differences across countries.

Changes to the curriculum have recently been put in place to provide a greater emphasis on participants developing person-centered plans, and it will be important to examine whether these changes result in differences in participant outcomes. In addition, future studies should examine the degree to which gains made through the Leadership Series and the achievement of personal goals created through the person-centered planning process are sustained over time through longitudinal studies of participants several years after training.

Although the field of disability, in recent years, has experienced many positive changes, there is still far to go before individuals with disabilities obtain their rightful place as valued contributing members of society. According to the World Health Organization and World Bank (2014), there are more than one billion people worldwide living with a disability. The majority of these individuals receive their education in segregated placements, are unemployed or under-employed, and lack meaningful relationships in their lives. Institutions continue to replace real homes for far too many individuals.

Leadership training for families and consumers has the potential to change these outcomes through its effectiveness in building a power base of advocates in the international movement for social justice and civil rights for people with disabilities. Graduates of the Series can attest to the power of unifying the individual voices and concerns of people with disabilities and their families into a shared vision and an increased momentum for positive change:

"I have met extraordinary people who have given me the strength to persevere, whether they were a past graduate of leadership or members of my class. This is the first time in my life I have been able to work on who I am, and that is the best gift I ever have been given".

\section{RefERENCES}

Balcazar, F., Keys, C., Bertram, J., \& Rizzo, T. (1996). Advocate development in the field of developmental disabilities: A data based conceptual model. Mental Retardation, 34, 341-351.

Barenock, T., \& Weick, C. (1998). Partners in policymaking. In: L. Ward (ed.), Innovations in advocacy and empowerment for people with intellectual disabilities (pp. 180-197). Chorley, UK: Lisieux Hall.
Family and consumer leadership 
Mary Schuh,

David Hagner, Ann Dillon, Beth Dixon
Caldwell, J. (2010). Leadership development of individuals with developmental disabilities in the self-advocacy movement. Journal of Intellectual Disability Research, 54, 1004-1014.

Chambers, C. R., Hughes, C., \& Carter, E. W. (2004). Parent and sibling perspectives on transition to adulthood. Education and Training in Developmental Disabilities, 39, 79-94.

Cunconan-Lahr, R., \& Brotherson, M. (1996). Advocacy in disability policy: Parents and consumers as advocates. Mental Retardation, 34, 352-358.

Deguara, M., Jelasi, O., Micallef, B., \& Callus, A. (2012). How we like to live when we have the chance. British Journal of Learning Disabilities, 40, 123-127.

Green, S. (2007). "We're tired, not sad": Benefits and burdens of mothering a child with a disability. Social Science and Medicine, 64, 150-163.

Grenwelge, C., \& Zhang, D. (2012). The effects of the Texas Youth Leadership Forum Summer Training on the self-advocacy abilities of high school students with disabilities. Journal of Disability Policy Studies, 24, 158-169.

Hess, R., Clapper, C., Hoekstra, K., \& Gibson, F. (2001). Empowerment effects of teaching leadership skills to adults with a severe mental illness and their families. Psychiatric Rehabilitation Journal, 24, 257-265.

Knox, M., Parmenter, T., Atkinson, N., \& Yazbeck, M. (2000): Family control: The views of families who have a child with an intellectual disability. Journal of Applied Research in Intellectual Disabilities, 13, 17-28.

Powers, L., Ward, N., Ferris, L., Nelis, T., Ward, M., Weick, C., \& Heller, T. (2002). Leadership by people with disabilities in self-determination systems change. Journal of Disability Policy Studies, 13, 125-133.

Reynolds, M. C. (2011). Understanding the Partners in Policymaking Program and the Impact of Participation on Parents of Children with developmental Disabilities in Missouri. Unpublished doctoral dissertation. University of Missouri-Kansas City. http:// hdl.handle.net/10355/10903. 91 pgs.

Soresi, S., Nota, L., \& Wehmeyer, M. (2011). Community involvement in promoting inclusion, participation and self-determination. International Journal of Inclusive Education, 15, 15-28.

Stringfellow, J., \& Muscari, K. (2003). A program of support for consumer participation in systems change. Journal of Disability Policy Studies, 14, 142-147.

Turnbull, H., Stowe, M., Agosta, J., Turnbull, A., Schrandt, S., \& Muller, J. (2007). Federal family and disability policy: Special relevance for developmental disabilities. Mental Retardation and Developmental Disabilities Research Reviews, 13, 114-120.
Turnbull, A., Taylor, E., Erwin., E., \& Soodak, L. (2006). Families, Professionals and Exceptionality: Positive outcomes through partnership and trust. $5^{\text {th }}$ ed. New Jersey: Pearson Education, Inc. Prentice Hall.

United Nations Department of Economic and Social Affairs. (2006). Convention on the Rights of Persons with Disabilities. Retrieved 12/09/2044 from http://www.un.org/disabilities/default.asp? navid $=15 \&$ pid $=150$.

Vargas, C. M., Arauza, C., Folsom, K., Luna Mdel, R., Gutiérrez, L., Frerking,P.O.,Shelton, K., Foreman,C., Waffle, D., Reynolds, R., \& Cooper, P. J. (2012). A community engagement process for families with children with disabilities: Lessons in leadership and policy. Maternal and Child Health Journal, 16, 21-30.

Wang, M., Mannan, H., Poston, D., Turnbull, A., \& Summers, J. (2004). Parents' perceptions of advocacy activities and their impact on family quality of life. Research \& Practice for Persons with Severe Disabilities, 29, 144-155.

World Health Organization and World Bank. (2014). World report on disability. http://www.who.int/ disabilities/world_report/2011/en/. 